\title{
TEKNIK PROGRESSIVE MUSCLE RELAXATION MEMPENGARUHI KADAR GLUKOSA DARAH PENDERITA DIABETES MELITUS TIPE 2
}

\author{
Puji Astuti \\ UNUSA, FKK, Prodi SI Keperawatan - Jl. Smea 57 Surabaya \\ Email : Pujiastuti@unusa.ac.id
}

\begin{abstract}
ABTRACT: The high uncontrolled blood glucose level in people with Diabetes Mellitus (DM) is still often found that is resulted from the factor of psychological stress. One of the interventions to help normalize the blood glucose level is progresive muscle relaxation (PMR). Therefore, this research was purposed to find out the effect of PMR towards blood glucose level in patients with DM type 2 (DMT2). This research was pre-experimental done by applying one group pretest posttest design. The population involved all patients with DMT2 without complications hospitalized in Surabaya Islamic General Hospital, in which 22 respondents were taken as the samples by using simple random sampling technique. The independent variable was PMR, whereas the dependent one was blood glucose level. The instrument used to measure blood glucose level was a glucometer. Moreover, the data were analyzed by using paired T-test with the significance level of $\alpha=0.05$. The result of research showed that before receiving PMR, the average blood glucose level was $238.40 \mathrm{mg} / \mathrm{dl}$, whereas before receiving PMR, the average blood glucose level was $125.68 \mathrm{mg} / \mathrm{dl}$. Moreover, the result of Paired T-test showed that $p=0.000<0.05$ so that $H_{0}$ was rejected, illustrating that there was an effect of PMR toward blood glucose level before and after receiving PMR Discussion: In conclusion, PMR could decrease blood glucose level Therefore, the nurses in hospital should be able to do PMR done at home to balance blood glucose level in patients with $D M T 2$ so that they can be more relaxed and independent.
\end{abstract}

\begin{abstract}
ABSTRAK: Kadar gula darah penderita DM yang tinggi atau tidak terkendali masih banyak dijumpai diantaranya karena faktor stres psikologi. Salah satu intervensi dalam membantu menormalkan kadar gula darah ini menggunakan teknik relaksasi (PMR) tujuan penelitian ini untuk mengetahui pengaruh PMR terhadap kadar gula darah pada pasien DMT2. Desain penelitian ini menggunakan Pra Experiment dengan mengunakan pendekatan One Group Pretest Postest Design. Populasinya adalah semua pasien diabetes mellitus tipe 2 tanpa komplikasi di RSI Surabaya. Sampel diambil secara simple random sampling dengan besar sample 22 responden. Variabel independen adalah PMR dan variabel dependen adalah KGD. Instrumen yang digunakan untuk mengukur KGD adalah glukometer test. Data dilakukan dengan uji analisis paired t-test dengan tingkat kemaknaan $\alpha<0.05$. Hasil penelitian didapatkan rata-rata kadar gula darah sebelum di berikan PMR $238.40 \mathrm{mg} / \mathrm{dl}$ dan rata-rata kadar gula sesudah diberikan PMR $125.68 \mathrm{mg} / \mathrm{dl}$. Berdasarkan uji paired t-test di dapatkan tingkat signifikan $\mathrm{p}=$ $0,000<0,05$ sehingga $\mathrm{H}_{0}$ ditolak, ada pengaruh terhadap KGD sebelum dilakukan PMR dan sesudah diberikan PMR. Saran diharapkan agar perawat rumah sakit mampu melaksanakan teknik PMR untuk menyeimbangkan nilai kadar gula darah pada pasien DMT2 agar bisa lebih rileks, lebih mandiri dan dapat dilakukan di rumah.
\end{abstract}

Kata kunci : Diabetes mellitus, Kadar gula darah, PMR 


\section{PENDAHULUAN}

Penyakit diabetes mellitus ( DM ) adalah ketidakmampuan organ pankreas memproduksi hormon insulin atau sel tubuh tidak dapat menggunakan insulin yang telah dihasilkan organ pankreas secara baik. Akibat dari kelainan ini, maka kadar gula darah (glukosa) akan meningkat tidak terkendali. Kadar gula (glukosa) pada pasien DM harus dipertahankan pada nilai normal, dijaga dan dikontrol, dalam artian tidak boleh terlalu tinggi dan juga tidak boleh terlalu rendah dari ambang normal. Ambang normal gula darah manusia adalah 60-120 mg/dL pada waktu puasa dan dibawah 140 $\mathrm{ml} / \mathrm{dL}$ dua jam sesudah makan (Sutanto, 2013). Kadar gula darah penderita DM yang tinggi atau tidak terkendali masih banyak dijumpai diantaranya karena faktor stres psikologi. Stres psikolologi dapat dikendalikan dengan pemberian terapi relaksasi, sehingga pada akhirnya dapat membantu menormalkan kadar gula darah, namun intervensi keperawatan berupa pemberian relaksasi masih belum optimal dilaksanakan.

Data dari studi global menunjukan bahwa jumlah penderita Diabetes Melitus pada tahun 2011 telah mencapai 366 juta orang. Jika tidak ada tindakan yang dilakukan, jumlah ini diperkirakan akan meningkat menjadi 552 juta pada tahun 2030 (IDF, 2011). Diabetes mellitus telah menjadi penyebab kematian dari 4,6 juta jiwa. Selain itu pengeluaran biaya kesehatan untuk diabetes mellitus telah mencapai 465 miliar USD (IDF, 2011). International Diabetes Federation (IDF) memperkirakan bahwa sebanyak 183 juta orang tidak menyadari bahwa mereka mengidap DM. Sebesar 80\% orang dengan DM tinggal di negara berpenghasilan rendah dan menengah, (IDF, 2011).

Menurut data Badan Kesehatan Dunia (WHO), Indonesia menempati urutan ke 4 terbesar dalam jumlah penderita diabetes mellitus di dunia setelah India, China, dan Amerika Serikat. Jumlah penderita diabetes melitus di Indonesia sekitar 17 juta atau mencapai 8,6 \% dari 220 juta populasi negeri ini. Pada tahun 2030 diperkirakan akan meningkat menjadi 21,3 juta penderita. Menurut penelitian epidemiologi prevalensi diabetes di Indonesia berkisar 1,5-2,3\% (Pusat Data Diabetes/ Departemen Komunikasi dan Informatika, 2008).

Data awal yang di peroleh jumlah penderita DM di Rumah Sakit Islam Surabaya pada tahun 2012 adalah 280 orang, sedangkan pada tahun 2013 adalah 272 orang. Dari wawancara pada 5 orang pasien DM tipe 2 yang berobat di poli penyakit dalam didapatkan 3 orang dengan kadar gula darah $>120 \mathrm{mg} / \mathrm{dl}, 2$ orang kadar gula darah 2 jam PP >140 mg/dl. Dari 5 orang tersebut yang mengeluh memiliki beban fikiran/masalah adalah 3 orang dengan skala stres $8-10$, dan 1 orang dengan skala stres 4-7, 1 orang 1-3. Oleh karena itu penderita DM tidak bisa diabaikan oleh perawat karena angka kejadiannya cukup besar.

Ada beberapa cara untuk menurunkan gula darah yaitu melakukan cek gula darah agar bisa mengontrol gula darah, berolahraga secara teratur, membatasi mengkonsumsi gula, makan sedikit tapi sering, diet, dan melakukan teknik relaksasi. Untuk menurunkan stres di beberapa Rumah Sakit upaya-upaya tersebut sudah sering bahkan sudah menjadi prosedur tetap untuk dilaksanakan seperti pemeriksaan laboratorium, klub senam diabet, konsultasi gizi dan penyuluhan 
kesehatan untuk pasien DM, namun pada intervensi khusus seperti relaksasi untuk menurunkan stres masih belum pernah dilakukan oleh perawat secara mandiri.

Teknik relaksasi merupakan salah satu tehnik pengelolaan diri yang didasarkan pada cara kerja sistem saraf simpatis dan parasimpatis. Salah satu terapi relaksasi adalah Relaksasi otot (progresive muscle relaxation); (Widyastuti \& Yulianti, 2004). Dalam relaksasi otot (progresive muscle relaxation) sendiri, individu akan diberikan kesempatan untuk mempelajari bagaimana cara menegangkan sekelompok otot tertentu kemudian melepaskan ketegangan itu. Bila sudah dapat merasakan keduanya, klien mulai membedakan sensasi pada saat otot dalam keadaan tegang dan rileks (Widyastuti, 2004). Sesuatu yang diharapkan disini adalah individu secara sadar untuk belajar merilekskan otot-ototnya sesuai dengan keinginannya melalui suatu cara yang sistematis. Subjek juga belajar mengenali keteganggan otot-ototnya dan berusaha untuk sedapat mungkin mengurangi atau menghilangkan ketegangan otot tersebut. Dari uraikan di atas, peneliti tertarik untuk meneliti "pengaruh pemberian teknik progresive muscle relaxation terhadap kadar glukosa darah pada penderita DM tipe 2" .

\section{METODE}

Pada penelitian ini, yang digunakan adalah Pra Experiment One Group Pretest Postest Design yang dijelaskan Notoatmodjo (2010). Dalam rancangan ini, observasi dilakukan sebanyak 2 kali yaitu sebelum pemberian tindakan Progressive muscle relaxation (pre-test) dan sesudah pemberian tindakan Progressive muscle relaxation (posttest). Populasi dalam penelitian ini adalah seluruh pasien DM tipe 2 tanpa komplikasi di rawat inap RSI Surabaya sebanyak 23 orang. Sampel dalam penelitian ini adalah sepasien DM tipe 2 tanpa komplikasi. Berdasarkan sampel pada penelitian ditentukan dengan rumus (Wasis, 2008) diperoleh besar sampel dalam penelitian ini adalah 22 orang.

Penelitian ini dilakukan selama 3 hari, dengan langkah sebagai berikut: (a). Peneliti melakukan penjelasan kepada pasien untuk dilakukan penelitian dan informed consent jika pasien sudah menandatangani informed consent dilanjutkan menjelaskan pada responden. (b). Pada hari pertama pada responden dilakukan pre test (pengukuran KGD) dan pengisian kuesioner, 10 menit setelah pre test, diberikan PMR yang pertama selama (8-15 menit) dan PMR yang kedua 4 jam setelah PMR pertama diberikan. (c). Pada hari kedua pada responden dilakukan PMR yang ketiga sampai dengan keempat. (d). Pada hari ketiga dilakukan PMR ke lima sampai dengan ke enam dan 2 jam setelah PMR keenam dilakukan post test (pengukuran KGD).

\section{HASIL}

Tabel 5.1 Distribusi frekuensi responden berdasarkan umur di RSI Surabaya Maret 2014 Umur

(tahun) Frekuensi $\quad$ Persentase \%

$\begin{array}{ccc}21-35 & 1 & 4.5 \\ 36-45 & 2 & 9.1 \\ 46-60 & 13 & 59.1 \\ >60 & 6 & 27.3 \\ \text { Total } & 22 & 100.0\end{array}$

Tabel 5.2 Distribusi frekuensi responden berdasarkan jenis kelamin di RSI Surabaya Maret 2014

\begin{tabular}{ccc}
\hline $\begin{array}{c}\text { Jenis } \\
\text { kelamin }\end{array}$ & $\begin{array}{c}\text { Frekuen } \\
\text { si }\end{array}$ & $\begin{array}{c}\text { Persentase } \\
\%\end{array}$ \\
\hline $\begin{array}{l}\text { Laki-laki } \\
\text { Perempua } \\
\mathrm{n}\end{array}$ & 8 & 36.4 \\
\hline Total & 14 & 63.6 \\
\hline
\end{tabular}


Tabel 5.3 Distribusi frekuensi responden berdasarkan mengonsumsi obat sebelum di RSI Surabaya Maret 2014

\begin{tabular}{|c|c|c|}
\hline & $\begin{array}{c}\text { Frekuen } \\
\text { si }\end{array}$ & $\begin{array}{c}\text { Persenta } \\
\text { se } \%\end{array}$ \\
\hline $\begin{array}{l}\text { Mengkonsum } \\
\text { si obat medis }\end{array}$ & 15 & 68.2 \\
\hline $\begin{array}{l}\text { Mengkonsum } \\
\text { si obat herbal } \\
\text { Tidak } \\
\text { mengkonsum } \\
\text { si obat }\end{array}$ & 5 & 22.8 \\
\hline Total & 22 & 100.0 \\
\hline
\end{tabular}

Tabel 5.4 Distribusi frekuensi responden berdasarkan penyakit infeksi penyerta di RSI Surabaya Maret 2014

\begin{tabular}{lcc}
\hline Jenis kelamin & $\begin{array}{c}\text { Frekuen } \\
\text { si }\end{array}$ & $\begin{array}{c}\text { Persenta } \\
\text { se } \%\end{array}$ \\
\hline $\begin{array}{l}\text { Ada penyakit } \\
\text { infeksi } \\
\text { penyerta } \\
\text { Tidak ada } \\
\text { penyakit } \\
\text { infeksi } \\
\text { penyerta }\end{array}$ & 4 & \\
\hline \multicolumn{1}{c}{ Total } & & 18.2 \\
\hline
\end{tabular}

Tabel 5.5 Distribusi tingkat stres responden di RSI Surabaya Maret 2014

\begin{tabular}{ccccc}
\hline $\begin{array}{c}\text { Penguk } \\
\text { uran } \\
\text { variabe }\end{array}$ & $\mathrm{N}$ & $\mathrm{N}$ & $\mathrm{M}$ & \\
$\mathrm{i})$ & $\mathrm{i}$ & $\mathrm{a}$ & $\mathrm{a}$ & $\mathrm{S}$ \\
& $\mathrm{n}$ & $\mathrm{x}$ & $\mathrm{n}$ & $\mathrm{D}$ \\
\hline & 3 & 8 & & \\
KGD &. &. & 6. & 6. \\
pre test & 0 & 0 & 8 & 7 \\
\hline
\end{tabular}

Tabel 5.6 Distribusi KGD (mg/dl) responden sebelum diberikan PMR di RSI

Surabaya Maret 2014

\begin{tabular}{cccccc}
\hline $\begin{array}{c}\text { Peng } \\
\text { ukur } \\
\text { an } \\
\text { (vari }\end{array}$ & & M & M & M & \\
abel) & N & in & X & a & S \\
KG & & 1 & 4 & 2 & D \\
D & & 7 & 2 & 3 & 0 \\
pre & 2 & 0 & 0. & 8. &. \\
test & 2 & 0 & 0 & 4 & 3 \\
\hline
\end{tabular}

Tabel 5.7 Distribusi KGD (mg/dl) responden sesudah diberikan PMR di RSI Surabaya

\begin{tabular}{|c|c|c|c|c|c|}
\hline $\begin{array}{c}\text { Peng } \\
\text { ukur } \\
\text { an }\end{array}$ & & M & M & M & \\
\hline (vari & & $\mathrm{i}$ & $\mathrm{a}$ & ea & $\mathrm{S}$ \\
\hline abel) & $\mathrm{N}$ & $\mathrm{n}$ & $\mathrm{x}$ & $\mathrm{n}$ & D \\
\hline & & 9 & 2 & 1 & 2 \\
\hline & & 3 & 1 & 2 & 8 \\
\hline KGD & & . & 8. & 5. & . \\
\hline post & 2 & 0 & 0 & 6 & 7 \\
\hline test & 2 & 0 & 0 & 8 & 2 \\
\hline
\end{tabular}

Tabel 5.8 Distribusi KGD (mg/dl) responden sebelum dan sesudah diberikan PMR di RSI Surabaya

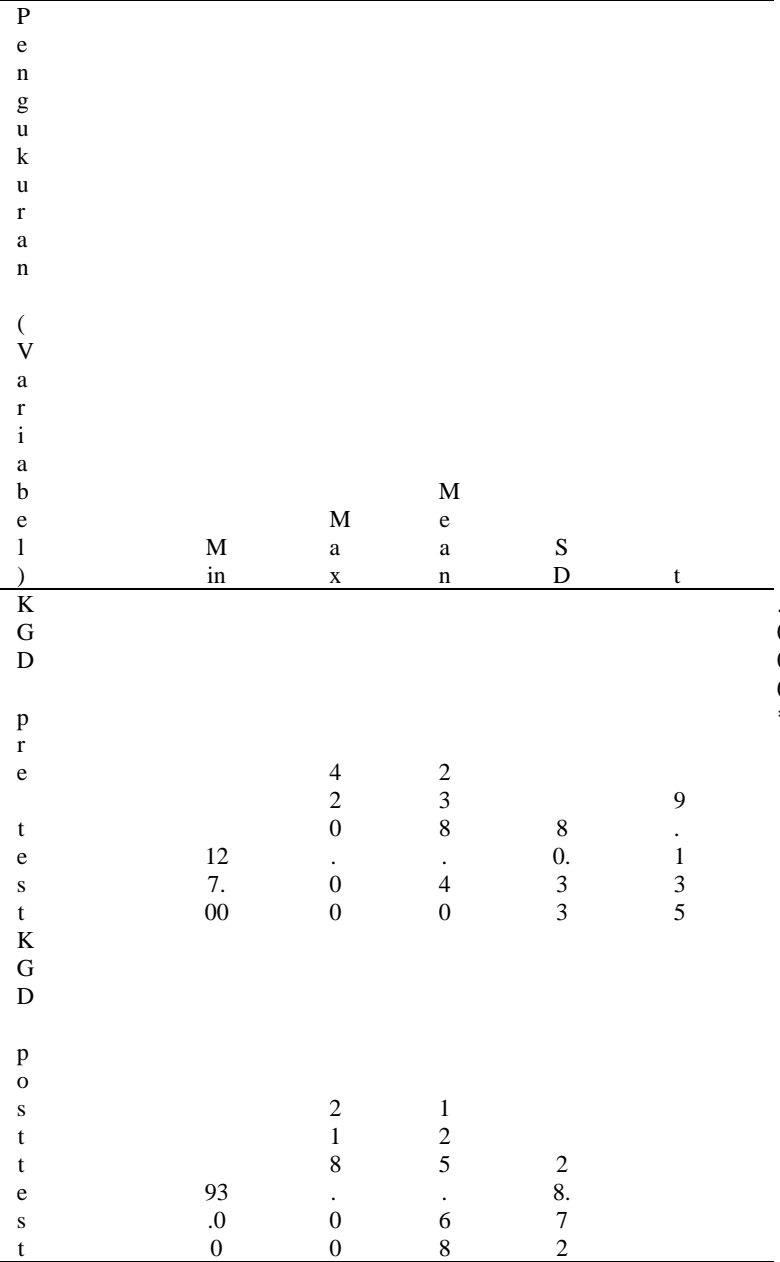

PEMBAHASAN

Kadar gula darah di pengaruhi banyak faktor yaitu makanan yang dimakan, waktu makan dan jumlah kalori yang masuk, aktifitas, obatobatan, penyakit infeksi, dan faktor psikologi (Racmawati, 2010). Obatobatan merupakan salah satu faktor yang dapat mempengaruhi kadar gula darah berdasarkan tabel 5.3 menunjukkan bahwa sebagian besar $(68.2 \%)$ pasien DM mengkonsumsi obat farmakologis sebelum masuk di RSI Surabaya. Ini sesuai dengan pendapat (Mahendra, dkk), keadaan ini disebabkan dosis harus sesuai dengan takaran yang dibutuhakan individu penderita. Jika dosis terlalu rendah maka akan timbul komplikasi kronis lebih dini, sedangakan dosis yang 
terlalu tinggi dan salah dalam cara pemakain dapat menimbulkan hipoglikemia.

Peningkatan kadar gula darah di pengaruhi banyak faktor salah satunya yaitu penyakit infeksi. Berdasarkan tabel 5.4 didapatkan (81.8\%) hampir seluruhnya tidak ada penyakit infeksi penyerta, tetapi 4 dari 22 reponden ada penyakit infeksi penyerta. Hal ini terjadi karena DMT2 sering tidak menunjukan gejala yang khas pada awalnya, sehingga diagnosis baru ditegakkan ketika pasien berobat untuk keluhan penyakit lain yang sebenarnya merupakan komplikasi dari diabetes tersebut.

Pada tabel 5.1 menunjukan bahwa sebagian besar (59.1 \%) responden berusia 46-60 tahun menderita DMT2. Hal ini sesuai dengan teori Guyton \& Hall (2012) resistensi insulin pada penderita DMT2 cenderung meningkat pada usia diatas 40 tahun. Hal tersebut disebabkan karena berkurangnya sensitifitas jaringan-jaringan tubuh terhadap insulin. Kejadian diabetes meliitus tipe 2 mencapai puncaknya pada usia 40-70 tahun hal ini disebabkan karena kelompok usia diatas 40 tahun mempunyai resiko lebih tinggi terkena DM akibat menurunya toleransi glukosa yang berhubungan dengan berkurangnya sensitifitas sel perifer terhadap infeksi insulin.

$\begin{array}{rrr}\text { Berdasarkan jenis } & \text { kelamin } \\ \text { wanita memang lebih mudah }\end{array}$ mengalami stres. Berbagai hal bisa menyebabkan tekanan emosional pada diri mereka, mulai pekerjaan, pengasuhan anak, sampai soal penampilan. Berdasarkan tabel 5.2 didapatkan sebagian besar (63.6\%) responden berjenis kelamin perempuan yang menderita DMT2. Hal ini dipicu oleh hormon selama kehamilan dan masa menopuase juga menyebabkan wanita rentan depresi. Selain itu kaum wanita juga berupaya lebih keras dalam menjaga hubungan dengan pasangan, mereka juga tak segan mencari pertolongan profesional jika menggalami gejala depresi, sehingga mereka lebih sering didiagnosis.

Berdasarkan hasil penelitian perempuan resiko lebih tinggi menggalami stres hal ini dikarenakan perempuan cenderung memikirkan masalah secara berlebihan. Bila menggalami stres perempuan cenderung makan-makanan ringan atau makanan dengan porsi yang lebih banyak dan itu beresiko tinggi mengalami obesitas karena adanya penumpukan lemak hal ini mengakibatkan beresiko tinggi terkena DM. Gaya hidup yang sehat juga memiliki peran penting dalam mencegah dan mengurangi resiko terjadinya peningkatan gula darah. Faktor yang dapat mempengaruhi penurunan gula darah yaitu, diit, obatobatan, latihan fisik/olahraga, dan tidak menggalami gangguan stres psikologi. Stres merupakan realitas kehidupan setiap hari, dan stres tidak dapat kita hindari tetapi kita harus mampu menanggulangi stres dalam hidup. Dalam mengalami stres psikologi seseorang tidak dapat memiliki perasaan tentram dan tidak nyaman dalam tubuh.

Respon relaksasi adalah kebalikan respon alarm dan respon tersebut mengembalikan tubuh seseorang pada keadaan seimbang. Pupil, pendengaran, tekanan darah, denyut jantung, penapasan dan sirkulasi kembali normal, dan otot-otot menjadi relaks. Melakukan teknik relaksasi dapat mengatasi stres dan kecemasan menjadi lebih baik, latihan ini bisa dilakukan setiap hari (Asih, 2002). Ada banyak teknik relaksasi yang dapat menaggulangi stres psikologi salah satunya yaitu Progressive muscle relaxation.

Progressive muscle relaxation merupakan suatu bentuk mind-body 
therapy, prosedur untuk mendapatkan reaksi pada otot melalui dua langkah, yaitu dengan memberikan suatu tegangan pada suatu kelompok otot, dan menghentikan tegangan tersebut kemudian memusatkan perhatian terhadap bagaimana otot tersebut menjadi rileks, merasakan sensasi rileks, dan ketegangan menghilang (Widyastuti, 2004). Latihan ini akan membantu meringankan keseluruhan tegangan dan tingkat stress, dan membantu ketika sedang merasa cemas. Ini juga dapat membantu mengurangi permasalahan fisik seperti sakit perut atau sakit kepala, sebagaimana juga membuat tidurnya lebih nyenyak. Orang dengan problem kecemasan seringkali sangat tegang sepanjang hari bahkan mereka tidak mengenal bagaimana rasanya rileks. Dengan berlatih teknik relaksasi PMR dapat mempelajari cara membedakan antara rasa otot yang tegang dan otot yang benar-banar rileks sepenuhnya. Kemudian, penderita bisa memulai memperkenalkan keadaan rileks ini ketika tanda pertama ketegangan otot yang menyertai perasaan cemas.

PMR dapat menurunkan kadar gula darah pada pasien DM dengan memunculkan kondisi rileks pada kondisi ini terjadi penurunan impuls saraf pada jalur eferen ke otak dimana aktivasi menjadi inhibisi. Perubahan impuls saraf ini menyebabkan perasaan tenang baik fisik maupun mental seperti berkurangnya denyut jantung, menurunya kecepatan metabolisme dalam hal ini mencegah peningkatan KGD. Untuk itu bagi responden dianjurkan untuk melakukan teknik PMR agar dapat menurunkan kadar gula darah menjadi seimbang atau normal.

Dalam PMR terdapat 15 gerakan dan harus dilakukan secara berurutan, dan saat melakukan PMR perhatian diarahkan untuk membedakan perasaan yang di alami saat kelompok otot dilemaskan dan dibandingkan ketika otot-otot dalam kondisi tegang. Namun bila yang bersangkutan tidak mampu memusatkan pikiran dalam melaksanakan PMR juga kurang membawa hasil yang maksimal, karena PMR merupakan salah satu bentuk mind-body therapy. Karena Relaksasi ini dapat memberikan keyamanan bagi klien, sehingga dapat menyeimbangkan kadar gula darah yang tidak normal.

Hubungan antara stres dan penyakit bukanlah hal baru. Selama berabadabad, para dokter telah menduga bahwa stres dapat mempengaruhi kesehatan seseorang secara berarti. Stres yang berkelanjutan menyebabkan aktivitas aksis HPA yang meningkat sehingga kadar kortisol meningkat yang diiringi oleh peningkatan glukose di sirkulasi. Di lain pihak kortisol juga mempengaruhi fungsi insulin terkait dalam hal sensivitas, produksi dan reseptor, sehingga glukose darah tidak bisa diseimbangkan ( Putra, 2011).

Hasil penelitian menunjukan 1 dari 22 responden ada yang tidak mengalami penurunan kadar gula darah, KGD yang meningkat tetap meningkat karena pasien tersebut mengalami penyakit infeksi lambung. Menurut (Mahendra dkk, 2008) pada pengidap diabetes menahun, otot serta saraf lambung juga mudah terganggu (akibat gangguan proses pengosongan lambung dan makanan yang tinggal lebih lama didalamya) dan komplikasi pada otot polos serta sistem saraf usus (khususnya usus besar). Kadar glukosa tinggi dalam darah bisa menjadi bahan toksik sehingga merusak saraf penderita diabetes menahun. Akibat komplikasi yang menyerang saraf usus membuat makanan sulit dicerna sehingga makanan lebih lama tinggal didalam lambung. Makanan yang lebih lama tinggal didalam lambung dapat menyebabkan gastritis karena membuat kerja lambung semakin berat 
sehingga memicu peningkatan asam lambung.

Progressive muscle ralaxation yang di ciptakan oleh Dr. Elmund Jacobson lima puluh tahun lalu di Amerika Serikat, adalah salah satu teknik yang khusus di desain untuk membantu meredakan ketengangan otot yang terjadi ketika sadar. Mekanisme PMR dalam menurunkan KGD pada pasien DMT2 erat kaitanya dengan stres yang di alami oleh pasien baik fisik maupun psikologis. Selama stres hormon-hormon yang mengarah pada peningkatan KGD seperti epineprin, kortisol, glukagon, ACTH, kortikosteroid, dan tiroid akan meningkat. Penilaian terhadap stressor mengakibatkan keteganggan otot yang mengirimkan stimulus ke otak dan membuat jalur umpan balik. Relaksasi PMR akan menghambat jalur tersebut dengan cara mengaktivasi cara kerja sistem saraf para simapatis dan memanipulasi hipotalamus melalui pemusatan pikiran untuk memperkuat sikap positif sehingga rangsangan stres terhadap hipotalamus berkurang.

Teknik ini mudah di pelajari dan di praktikan dalam berbagai lingkungan, bahkan dalam lingkungan yang rentan stres seperti tempat kerja atau rumah sakit. PMR juga dapat dilakukan di pagi dan sore hari guna membantu melepaskan tingkat ketegangan yang memuncak dalam aktifitas keseharian yang membuat stres. PMR ini dapat dilakukan di rumah, hanya membutuhkan waktu 8-15 menit, sehingga memungkinkan klien dan keluarga untuk melakukannya, tidak membutuhkan biaya yang mahal, dapat dipelajari sendiri oleh keluarga dan hampir tidak ada kontraindikasi.

\section{SIMPULAN}

Dari hasil penelitian yang dilakukan peneliti, maka peneliti menyimpulkan beberapa hal sebagai berikut: (1). Kadar gula darah pada penderita DMT2 di RSI Surabaya sebelum melakukan PMR seluruh responden memiliki kadar gula darah rata-rata $238.40 \mathrm{mg} / \mathrm{dl}$ (tinggi). (2). Kadar gula darah pada penderita DMT2 di RSI Surabaya sesudah melakukan PMR seluruh responden mengalami penurunan kadar gula darah rata-rata $125.68 \mathrm{mg} / \mathrm{dl}$ (normal). (3). Ada pengaruh pemberian teknik Progressive muscle realaxation terhadap kadar gula darah penderita diabetes tipe 2 di Rumah Sakit Islam Surabaya.

\section{DAFTAR PUSTAKA}

Ankrom, S (2008). Progressive Muscle Relaxation can help you reduce anxiety and preven panic: What is Progressive Muscle Relaxation? Diakses 23 Desember 2013.

Esther, C. Dally, J. Elliot, D (2010). Patofisiologi Aplikasi Pada Praktik Keperawatan. Jakarta, EGC

Departemen Kesehatan. 2005. Pharmaceutical Care untuk Penyakit Diabetes Melitus.

Eko, A (2010). Hubungan Aktivitas Fisik Dan Istirahat Dengan Kadar Gula Darah Pasien Diabetes Mellitus Rawat Jalan Rsud. Prof. Dr. Margono Soekardjo. Skripsi. Fakultas Ilmu Kesehatan Universitas Muhammadiyah Purwokerto Diakses 23 november 2013.

Fahmi, A (2010). Hipoglikemia (Kadar Gula Darah Rendah). Diakses 24 November 2013 dari

International Diabetes Federation (2011). One Adult In Ten Will Have Diabetes By 2030. [http://www.idf.org/mediaevents/press-releases/2011/diabetesatlas-8th-edition] [Diunduh pada 10 Desember 2013 pukul 17.45 WIB] 
Kariadi KS, Hartini (2009). Diabetes? Siapa takut!!. Bandung: Qonita

Lestari, D.P. (2009). Hidup Sehat Tanpa Penyakit. Yogyakarta: Penerbit Monce Publisher.

Mahendra, Diah Krisnatuti, dkk. (2008). Care your self diabetes mellitus. Jakarta : Penebar plus

Markam, Sumarno. (2009). Dasar - dasar neuroimunologi klinis. Jakarta, Sagung Seto.

Misnadiraly. (2006). Diabete Mellitus Mengenenali Gejala Menangulangi mencegah komplikasi. Jakarta: Pustaka popular Obor

Notoatmodjo, Soekidjo (2010). Metodelogi Penelitian Kesehatan. Jakarta, Rineka Cipta.

Putra, Suhartono, T. 2004. Naskah Lengkap PB Persadia. Simposium Diabetes Melitus untuk Dokter dan Diabetisi. Semarang: Universitas Diponegoro, pp 25-31.

Rahcmawati, Ova (2010). Hubungan Latihan Jasmani Terhadap Kadar Glukosa Darah Penderita Diabetes Melitus Tipe-2. Skipsi, Fakultas Kedokteran Universitas Sebelas Maret Surakarta.

Sutanto, Teguh (2013). Diabetes, deteksi, pencegahan, pengobatan, Yogyakarta : Buku Pintar.

Wasis (2008). Pedoman Riset Praktis untuk Profesi Perawat. Jakarta, EGC

Widyawati palupi dan yulianti Devi (2004). Manajemen stres National Safety Council, Jakarta: EGC56T 